\section{Digital dentistry: an overview of recent developments for CAD/CAM generated restorations}

\author{
F. Beuer, ${ }^{1}$ J. Schweiger ${ }^{2}$ and D. Edelhoff ${ }^{3}$
}

VERIFIABLE CPD PAPER
IN BRIEF

- CAD/CAM technology is widely available, but little is known about it by the general dental practitioner.

- This article informs the practitioner about recent developments in the field of digital dentistry.

- Information outlined in this article could aid the cost-effective production of dental prostheses.

As in many other industries, production stages are increasingly becoming automated in dental technology. As the price of dental laboratory work has become a major factor in treatment planning and therapy, automation could enable more competitive production in high-wage areas like Western Europe and the USA. Advances in computer technology now enable cost-effective production of individual pieces. Dental restorations produced with computer assistance have become more common in recent years. Most dental companies have access to CAD/CAM procedures, either in the dental practice, the dental laboratory or in the form of production centres. The many benefits associated with CAD/CAM generated dental restorations include: the access to new, almost defect-free, industrially prefabricated and controlled materials; an increase in quality and reproducibility and also data storage commensurate with a standardised chain of production; an improvement in precision and planning, as well as an increase in efficiency. As a result of continual developments in computer hardware and software, new methods of production and new treatment concepts are to be expected, which will enable an additional reduction in costs. Dentists, who will be confronted with these techniques in the future, require certain basic knowledge if they are to benefit from these new procedures. This article gives an overview of CAD/CAM-technologies and systems available for dentistry today.

\section{DEFINITION}

The term 'CAD/CAM' in dental technology is currently used as a synonym for prostheses produced by 'milling technology'. This is not entirely correct. CAD is the abbreviation for 'computer-aided design' and CAM stands for 'computeraided manufacturing'. The term 'CAD/ CAM' does not provide any information on the method of fabrication.

All CAD/CAM systems consist of three components:

1. A digitalisation tool/scanner that transforms geometry into digital data that can be processed by the computer
2. Software that processes data and, depending on the application, produces a data set for the product to be fabricated

3. A production technology that transforms the data set into the desired product.

\section{CAD/CAM PRODUCTION CONCEPTS IN DENTISTRY}

Depending on the location of the components of the CAD/CAM systems, in dentistry three different production concepts are available:

- chairside production

- laboratory production

- centralised fabrication in a production centre.

\section{a) Chairside production}

Assistant Professor, ${ }^{2} \mathrm{Head}$ of Laboratory, ${ }^{3}$ Associa Professor, Department of Prosthodontics, Ludwig Maximilians University, Munich, Germany Correspondence to: Dr Florian Beuer, Pacific Dental Institute, 12750 SW 68th Avenue, Portland, Oregon, 97223, USA

Email:florian.beuer@med.uni-muenchen.de

\section{Refereed Paper}

Accepted 28 March 2008

DOI: $10.1038 /$ sj.bdj.2008.350

${ }^{\bullet}$ British Dental Journal 2008; 204: 505-511
All components of the CAD/CAM system are located in the dental surgery. Fabrication of dental restorations can thus take place at chairside without a laboratory procedure. The digitalisation instrument conventional impression in most clinical is an intra-oral camera, which replaces a situations. This saves time and offers the patient indirectly fabricated restorations at one appointment. At present, only the Cerec ${ }^{\circledR}$ System (Sirona) offers this possibility. Other producers also plan to introduce chairside CAD/CAM systems to the market. Since the $\mathrm{Cerec}^{\circledR}$ system functions with water-cooling, a variety of materials can be processed, from glass-ceramic to high performance oxide ceramic. Clinical observations on ceramic inlays are available over a period of 21 years. Scientific literature reported success rates for CAD/CAM produced inlays of 90\% after ten years and $85 \%$ after 12 and 16 years. ${ }^{1-3}$ Historically, this system was the first CAD/CAM system in dentistry and is currently available in its third product generation. One of the benefits of this very mature system is the software that has been supplemented by a very exact three-dimensional reconstruction of the occlusal surface.

\section{b) Laboratory production}

This variant of production is the equivalent to the traditional working sequence 
between the dentist and the laboratory. The dentist sends the impression to the laboratory where a master cast is fabricated first. The remaining CAD/CAM production steps are carried out completely in the laboratory. With the assistance of a scanner, three-dimensional data are produced on the basis of the master die. These data are processed by means of dental design software. After the CAD-process the data will be sent to a special milling device that produces the real geometry in the dental laboratory. Finally the exact fit of the framework can be evaluated and, if necessary, corrected on the basis of the master cast. The ceramist carries out the veneering of the frameworks in a powder layering or overpressing technique. ${ }^{4-7}$

\section{c) Centralised production}

The third option of computer-assisted production of dental prostheses is centralised production in a milling centre. In this variation, it is possible for 'satellite scanners' in the dental laboratory to be connected with a production centre via the Internet. Data sets produced in the dental laboratory are sent to the production centre for the restorations to be produced with a CAD/CAM device. Finally, the production centre sends the prosthesis to the responsible laboratory. Thus, production steps 1 and 2 take place in the dental laboratory, while the third step takes place in the centre. ${ }^{5,8}$ As a result, the configuration of the prosthesis remains in the hands of the dental technician. The benefit of outsourcing CAM production is to be found in the small investment requirement, since only the digitalisation tool and software have to be purchased, still having access to a high quality production process. In addition, this procedure results in greater independence, since there is no relation to a particular production technology (such as, eg milling technology). It must, however, be noted that presently almost all CAD/CAM systems are only available as closed systems. In other words, if one acquires a scanner from one manufacturer, this implies, in the case of a closed system, that there is only access to that manufacturer's processes and line of products. In addition, the dental laboratory loses the income

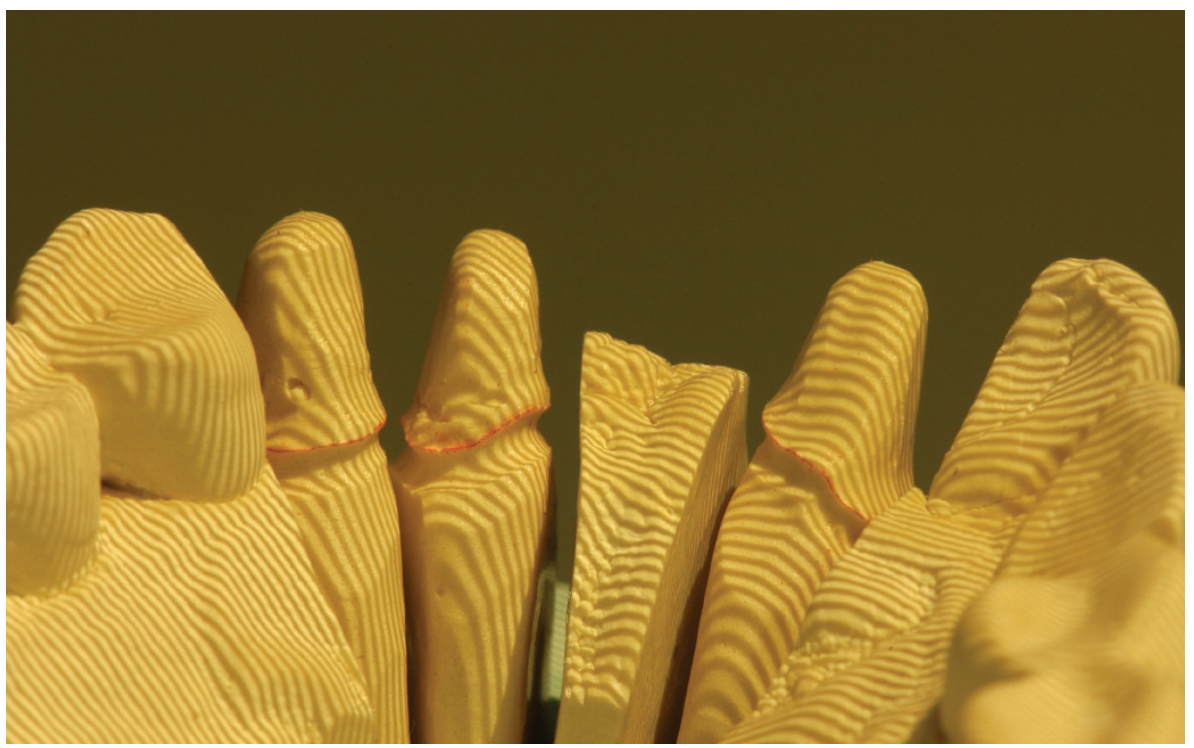

Fig. 1 White light projector pattern during the scanning process by an optical scanner

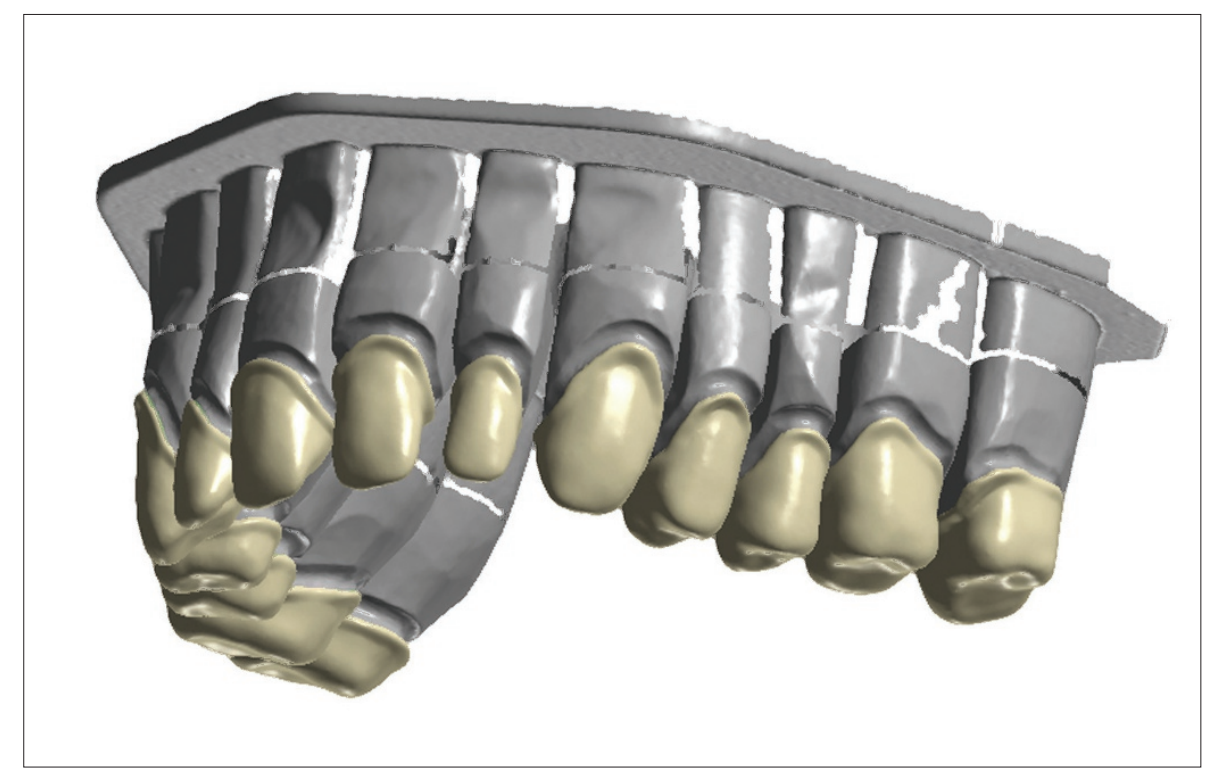

Fig. 2 Screen-shot of CAD-construction of 14 single crown copings

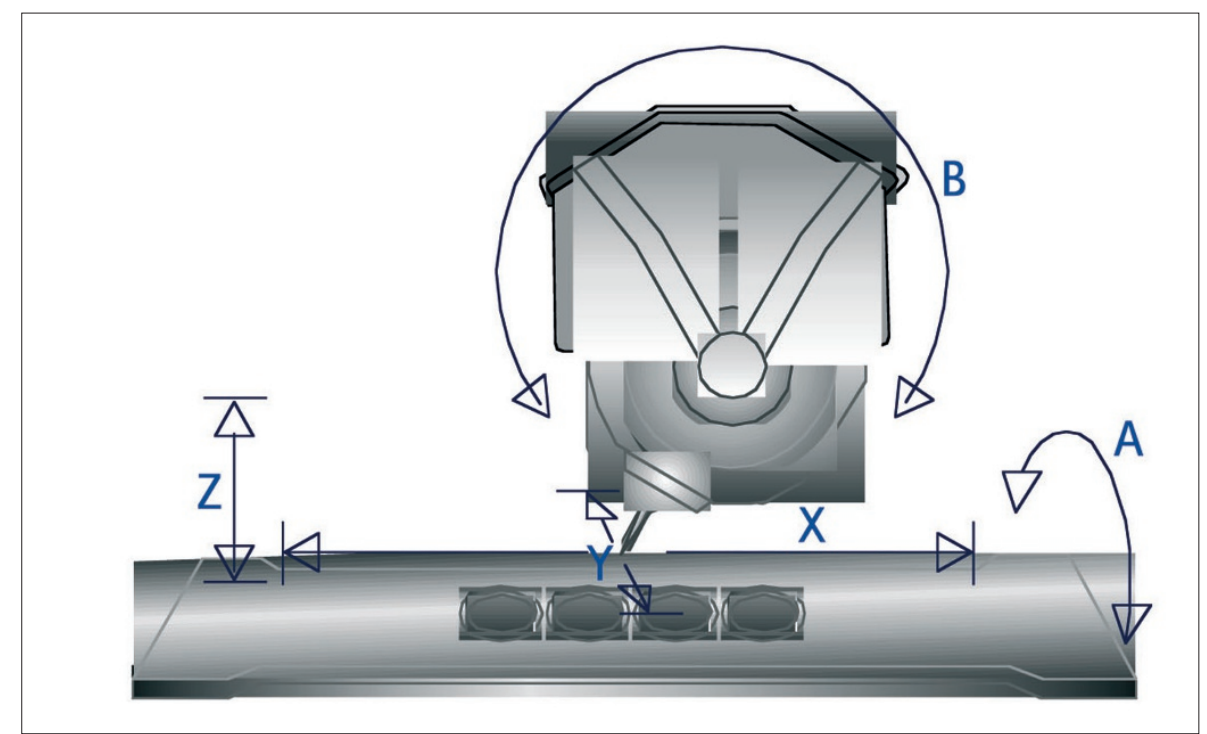

Fig. 3 Different possibilities of the working axis: 3 spatial directions $X, Y$ and $Z$ ( 3 axis milling devices); 3 spatial directions $X, Y, Z$ and tension bridge $A$ ( 4 axis milling devices); 3 spatial directions $X, Y, Z$, tension bridge $A$ and milling spindle $B$ (5 axis milling devices) 
from producing the framework, since it is fabricated in the production centre.

Many production centres also offer laboratories without a scanner the possibility of sending the master cast to the centre for scanning, designing and fabrication. The additional veneering of the frameworks for prosthetic restorations is carried out in the dental laboratory.

Recently, dentists have been offered the possibility of sending the impression directly to the production centre (biodentis). This application is presently limited to ceramic inlays only.

An additional simplification in CAD/ CAM production consists of intraoral data collection (optical impression). This means a digitalisation of what is now only an 'analogue' step in the production process. This could lead to additional improvement in quality and cost reduction. New software developments will make it possible to directly judge the quality of the preparation intraorally, before data are finally sent to the dental laboratory or production centre.

\section{CAD/CAM COMPONENTS}

\subsection{Scanner}

Under the term 'scanner' one understands, in the area of dentistry, data collection tools that measure threedimensional jaw and tooth structures and transform them into digital data sets. Basically there are two different scanning possibilities:

- optical scanners

- mechanical scanners.

\section{a) Optical scanners}

The basis of this type of scanner is the collection of three-dimensional structures in a so-called 'triangulation procedure'. Here, the source of light (eg laser) and the receptor unit are in a definite angle in their relationship to one another. Through this angle the computer can calculate a three-dimensional data set from the image on the receptor unit. ${ }^{9}$ Either white light projections or a laser beam can serve as a source of illumination (Fig. 1). The following can be named as examples of optical scanners on the dental market:

- Lava Scan ST (3M ESPE, white light projections)
- Everest Scan (KaVo, white light projections)

- es1 (etkon, laser beam).

\section{b) Mechanical scanner}

In this scanner variant, the master cast is read mechanically line-by-line by means of a ruby ball and the three-dimensional structure measured. The Procera Scanner from Nobel Biocare (Göteborg) is the only example for mechanical scanners in dentistry. This type of scanner is distinguished by a high scanning accuracy, whereby the diameter of the ruby ball is set to the smallest grinder in the milling system, with the result that all data collected by the system can also be milled. ${ }^{5,10}$ The drawbacks of this data measurement technique are to be seen in the inordinately complicated mechanics, which make the apparatus very expensive with long processing times compared to optical systems.

\subsection{Design software}

Special software is provided by the manufacturers for the design of various kinds of dental restorations. With such software, crown and fixed partial dentures (FPD) frameworks can be constructed on the one hand (Fig. 2); on the other hand, some systems also offer the opportunity to design full anatomical crowns, partial crowns, inlays, inlay retained FPDs, as well as adhesive FPDs and telescopic primary crowns. ${ }^{11}$ The software of CAD/CAM systems presently available on the market is being continuously improved. The latest construction possibilities are continuously available to the user by means of updates. The data of the construction can be stored in various data formats. The basis therefore is often standard transformation language (STL) data. ${ }^{9}$ Many manufacturers, however, use their own data formats, specific to that particular manufacturer, with the result that data of the construction programs are not compatible with each other.

The systems available on the market are differentiated mostly in their construction software. While many systems emphasise an indication spectrum that is as broad as possible, other manufacturers place emphasis on intuitive use and user-friendliness.

\subsection{Processing devices}

The construction data produced with the CAD software are converted into milling strips for the CAM-processing and finally loaded into the milling device. Processing devices are distinguished by means of the number of milling axes:

- 3-axis devices

- 4-axis devices

- 5-axis devices.

\section{a) 3-axis milling devices}

This type of milling device has degrees of movement in the three spatial directions. Thus, the mill path points are uniquely defined by the $\mathrm{X}-, \mathrm{Y}-$, and $\mathrm{Z}$ - values (Fig. 3). The calculation investment is therefore minimal. A milling of subsections, axis divergences and convergences, however, is not possible. This demands a virtual blocking in such areas. All 3-axis devices used in the dental area can also turn the component by $180^{\circ}$ in the course of processing the inside and the outside. The advantages of these milling devices are short milling times and simplified control by means of the three axes. As a result, such milling devices are usually less costly than those with a higher number of axes.

Examples of 3-axis devices: inLab (Sirona), Lava (3M ESPE), Cercon brain (DeguDent).

\section{b) 4-axis milling devices}

In addition to the three spatial axes, the tension bridge for the component can also be turned infinitely variably (Fig. 3). As a result it is possible to adjust bridge constructions with a large vertical height displacement into the usual mould dimensions and thus save material and milling time.

Example: Zeno (Wieland-Imes).

\section{c) 5-axis milling devices}

With a 5-axis milling device there is also, in addition to the three spatial dimensions and the rotatable tension bridge (4th axis), the possibility of rotating the milling spindle (5th axis) (Fig. 3). This enables the milling of complex geometries with subsections, as for example, lower jaw FPDs on converging abutment teeth (end molar tipped towards the medial plane) (Fig. 4), or also crown and FPD substructures that, 
as a result of anatomically reduced formation, demonstrate converging areas in the exterior of the frame.

Example in the Laboratory Area: Everest Engine (KaVo).

Example in the Production Centre: HSC Milling Device (etkon).

The quality of the restoration does not necessarily increase with the number of processing axes. The quality results much more from the result of the digitalisation, data processing and production process.

\section{MILLING VARIANTS}

\section{a) Dry processing}

Dry processing is applied mainly with respect to zirconium oxide blanks with a low degree of pre-sintering. This offers several benefits:

- Minimal investment costs for the milling device

- No moisture absorption by the die $\mathrm{ZrO}_{2}$ mould, as a result of which there are no initial drying times for the $\mathrm{ZrO}_{2}$ frame prior to sintering.

Disadvantages:

- The lower degree of pre-sintering results in higher shrinkage values for the frameworks.

Some manufacturers also offer the option of milling resin material in a dry milling process [Zeno 4030 (WielandImes), Lava Form and Cercon brain].

\section{b) Wet milling}

In this process the milling diamond or carbide cutter is protected by a spray of cool liquid against overheating of the milled material. This kind of processing is necessary for all metals and glass ceramic material in order to avoid damage through heat development. 'Wet' processing is recommended, if zirconium oxide ceramic with a higher degree of pre-sintering is employed for the milling process. A higher degree of pre-sintering results in a reduction of shrinkage factor and enables less sinter distortion.

Examples: Everest (KaVo), Zeno 8060 (Wieland-Imes), inLab (Sirona).

\section{MATERIALS FOR CAD/CAM PROCESSING}

The list of various materials for processing by CAD/CAM devices depends on

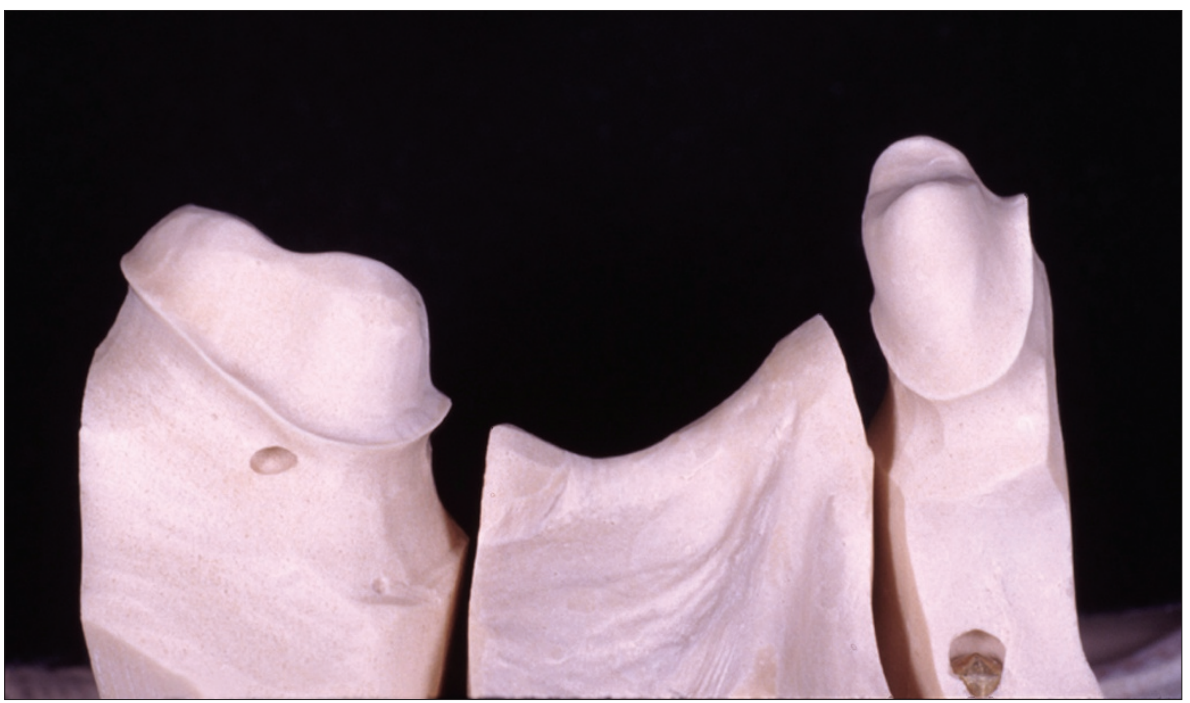

Fig. 4 Pinned master cast of converging abutment teeth for a fixed partial denture in the mandible. At least a 4 milling axis is required for the milling unit to fabricate a substructure for this situation

Table 1 Selection of resin materials for CAD/CAM systems

\begin{tabular}{l|l|l|l}
\hline Name & Manufacturer & $\begin{array}{l}\text { CAD/CAM } \\
\text { system }\end{array}$ & Description \\
\hline CAD-Waxx & Vita & inLab & $\begin{array}{l}\text { Filler-free acrylic polymer for lost } \\
\text { wax technique }\end{array}$ \\
\hline Cercon base cast & DeguDent & Cercon & $\begin{array}{l}\text { Residue-free cauterisable resin for lost } \\
\text { wax technique }\end{array}$ \\
\hline Everest C-Cast & KaVo & Everest & $\begin{array}{l}\text { Residue-free cauterisable resin for lost } \\
\text { wax technique }\end{array}$ \\
\hline CAD-Temp Block & Vita & Cerec 3, inLab & $\begin{array}{l}\text { Fibre-free acrylic polymer with micro-filler } \\
\text { for long-term temporary full and partial } \\
\text { crowns and FPDs up to two pontics }\end{array}$ \\
\hline $\begin{array}{l}\text { Everest C-Temp } \\
\text { Artegral } \\
\text { imCrown }\end{array}$ & KaVo & Everest & $\begin{array}{l}\text { Fibre reinforced polymer for long-term } \\
\text { temporary crowns and FPD frameworks, } \\
\text { requiring an additional veneering }\end{array}$ \\
\hline
\end{tabular}

the respective production system. Some milling devices are specifically designed for the production $\mathrm{ZrO}_{2}$ frames, others cover the complete palette of materials from resins to glass ceramics and high performance ceramics. The following materials can normally be processed on dental CAD/CAM devices:

\section{a) Metals}

At present, titanium, titanium alloys and chrome cobalt alloys are processed using dental milling devices. The milling of precious metal alloys has been shown to be of no economic interest, due to the high metal attrition and the high material costs.

Examples: coron (etkon: non-precious metal alloy), Everest Bio T-Blank (KaVo, pure titanium).

\section{b) Resin materials}

On the one hand, resin materials can be used for the milling of lost wax frames for casting technology; on the other hand, it is possible to use resin materials directly as crown and FPD frameworks for long-term provisional or for full anatomical longterm temporary prostheses (Table 1). Prefabricated semi-individual polymer blanks (semi-fınished) with a dentine enamel layer are provided by one manufacturer (artegral imCrown, Merz Dental). The exterior contour conforms to an anatomically complete anterior tooth crown, while the internal aspect of the crown is milled out of the internal volume of the blank.

\section{c) Silica based ceramics}

Grindable silica based ceramic blocks are offered by several CAD/CAM systems 
for the production of inlays, onlays, veneers, partial crowns and full crowns (fully anatomical, anatomically partially reduced) (Table 2). In addition to monochromatic blocks, various manufacturers now offer blanks with multicoloured layers [Vitablocs TriLuxe (Vita), IPS Empress CAD Multi (IvoclarVivadent)], for the purpose of full anatomical crowns. Due to their higher stability values, lithium disilicate ceramic blocks are particularly important in this group; they can be used for full anatomical anterior and posterior crowns, for copings in the anterior and posterior region and for three-unit FPD frameworks in the anterior region due to their high mechanical stability of $360 \mathrm{MPa} .{ }^{12-15}$ Glass ceramics are particularly well suited to chairside application as a result of their translucent characteristics, similar to that of natural tooth structure; they provide aesthetically pleasing results even without veneering. As a result of their relatively high portion of glass, these ceramics are, in contrast to oxide ceramics, etchable with hydrofluoric acid and thus can be inserted very well using adhesive systems. ${ }^{16,17}$

\section{d) Infiltration ceramics}

Grindable blocks of infiltration ceramics are processed in porous, chalky condition and then infiltrated with lanthanum glass. All blanks for infiltration ceramics originate from the Vita In-Ceram system (Vita) and are offered in three variations:

- Vita In-Ceram Alumina $\left(\mathrm{Al}_{2} \mathrm{O}_{3}\right)$ : suitable for crown copings in the anterior and posterior region, three-unit FPD frameworks in the anterior region ${ }^{18}$

- Vita In-Ceram Zirconia (70\% $\mathrm{Al}_{2} \mathrm{O}_{3}$, $30 \% \mathrm{ZrO}_{2}$ ): suitable for crown copings in the anterior and posterior region, three-unit FPD frameworks in the anterior and posterior region. Thanks to its superior masking ability this ceramic is suitable for discoloured abutment teeth ${ }^{19,20}$

- VITA In-Ceram Spinell $\left(\mathrm{MgAl}_{2} \mathrm{O}_{4}\right)$ : has the highest translucency of all oxide ceramics and is thus recommended for the production of highly aesthetic anterior crown copings, in particular on vital abutment teeth and in the case of young patients.

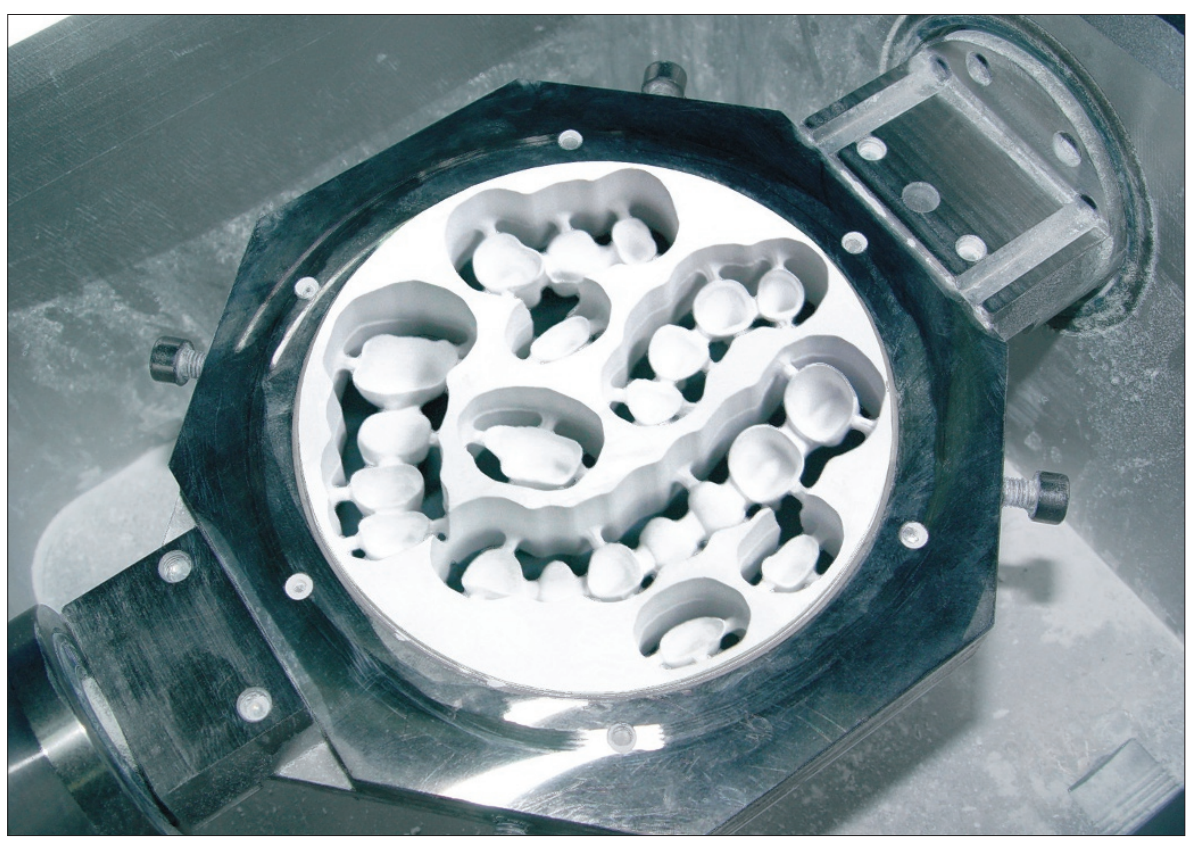

Fig. 5 Enlarged zirconium oxide after the milling process before sintering to the desired dimensions

\section{e) Oxide high performance ceramics}

At present, aluminum oxide and zirconium oxide are offered as blocks for CAD/CAM technology.

\section{Aluminum Oxide $\left(\mathrm{Al}_{2} \mathrm{O}_{3}\right)$}

This oxide high performance ceramic is ground in a pre-sintered phase and is then sintered at a temperature of $1520^{\circ} \mathrm{C}$ in the sintering furnace. Aluminium oxide is indicated in the case of crown copings in the anterior and posterior area, primary crowns and three-unit anterior FPD frameworks. The ground frames can be individually stained in several colours with Vita In-Ceram AL Coloring Liquid. ${ }^{5,21-23}$ Examples of grindable aluminum oxide blocks: In-Ceram AL Block (Vita), inCoris Al (Sirona) available in an ivory-like colour (Color F 0.7).

\section{Yttrium stabilised zirconium} oxide $\left(\mathrm{ZrO}_{2}, \mathrm{Y}\right.$-TZP)

Zirconium dioxide is a high-performance oxide ceramic with excellent mechanical characteristics. Its high flexural strength and fracture toughness compared with other dental ceramics offer the possibility of using this material as framework material for crowns and FPDs, and, in appropriate indications, for individual implant abutments. The addition of three molecules of $\mathrm{Y}_{2} \mathrm{O}_{3}$ results in a stabilising tetragonal phase at room temperature, which, as a result of a transition to a monoclinic phase can prevent the progression of cracks in the ceramic (Transformation strengthening). ${ }^{24-27}$ Examples of Zirconium oxide blocks: Lava Frame (3M ESPE), Cercon Smart Ceramics (DeguDent), Everest ZS und ZH (KaVo), inCoris Zr (Sirona), In-Ceram YZ (Vita), zerion (etkon) and Zeno Zr (Wieland-Imes)

\section{Processing can take place in different density stages}

\section{a) Green stage processing}

Green stage: blank without heat treatment, ie an object pressed from ceramic powder and binding agents.

Since there was no pre-sintering, the object is as soft as chalk. This permits very easy processing, but results, due to the low degree of stability, in great problems in transport and application. Processing is by means of carbide metal grinders without liquid cooling. The green stage has an open porosity, and in firing a 25\% linear shrinkage is to be expected. At present, zirconium oxide is not processed as a green stage in any of the CAD/CAM systems on the market.

\section{b) White stage processing}

White stage: pre-sintered blanks.

As a result of the thermal pre-treatment the organic compressing additives have vanished and the blank has an adequate 
stability. As a result of pre-sintering, the white body has already had shrinkage of approximately 5\%. In the case of CAD/ CAM production of objects from white bodies, the subsequent shrinkage of some 20\% (linear) must be taken into consideration. Processing of white stage can be either with carbide metal grinders without water cooling or with diamond grinders with liquid cooling (Fig. 5). ${ }^{8,28}$

\section{c) Processing in hot isostatic pressing condition}

Some systems also process zirconium oxide in HIP (hot isostatic pressed) condition with diamond tools and water cooling. The advantages and disadvantages are as follows. ${ }^{15,29,30}$

Advantages:

- No sinter shrinkage, as a result no sinter distortions

- No sinter furnace necessary

- No additional time needed for sintering procedure.

\section{Disadvantages:}

- Devices with high rigidity and stability necessary

- Longer milling times, resulting in lower utilisation of devices

- High wear of the cutters

- No coloured blanks available on the market yet.

\section{FUTURE TECHNOLOGIES}

\section{Generative production methods}

Generative production methods are special CAD/CAM methods, which, in contrast to grinding technology, do not work by subtracting, but rather by adding material. In the dental area there are some areas of application for which this technology is already applied. In some production centres, so-called 'laser sintering devices' are used to produce crown and bridge frames from chrome cobalt alloys. Since the productivity of such devices is very high, dental restorations can be produced very cost-effectively. Basically, geometries are conceivable with this technology that cannot be realised with grinding technology.

\section{SIGNIFICANCE FOR THE DENTIST}

In recent years, the use of CAD/CAM technology has above all strongly

\section{Table 2 Selection of glass ceramic materials for CAD/CAM systems}

\begin{tabular}{l|l|l|l} 
Name & Manufacturer & $\begin{array}{l}\text { CAD/CAM } \\
\text { system }\end{array}$ & Description \\
\hline Vitablocs Mark II & Vita & Cerec 3, inLab & $\begin{array}{l}\text { Monochrome for inlays, onlays, veneers } \\
\text { and full crowns }\end{array}$ \\
\hline IPS e.max CAD & Ivoclar Vivadent & inLab, Everest & $\begin{array}{l}\text { Monochrome for full anatomical crowns, } \\
\text { copings and anterior three-unit FPDs }\end{array}$ \\
\hline Vitablocs TriLuxe & Vita & Cerec 3, inLab & $\begin{array}{l}\text { Polychromatic for inlays, onlays, veneers } \\
\text { and full crowns }\end{array}$ \\
\cline { 2 - 4 } $\begin{array}{l}\text { IPS Empress } \\
\text { CAD Multi }\end{array}$ & Ivoclar Vivadent & inLab & $\begin{array}{l}\text { Polychromatic for inlays, onlays, veneers } \\
\text { and full crowns }\end{array}$ \\
\hline
\end{tabular}

influenced dental-technical production procedures. If one ignores chairside prostheses, the significance of this technology for the dentist is not immediately clear. In recent years, CAD/CAM production has clearly expanded the palette of materials for dental prostheses by providing access to new ceramic materials with high dependability. ${ }^{15,28-31}$ The stability values of zirconium oxide ceramics permit, in many areas of indication, the use of this material as an alternative to metal frames for permanent prostheses. ${ }^{30}$

The production of long-term temporary prostheses has, as a result of the use of a virtual wax up on the computer, become faster, more convenient and more predictable. This method has already been implemented by computer-generated long-term temporary restorations, since it can be modified, by changing the form, to the functional and aesthetic satisfaction of the patient during a clinical test phase. The production of the definitive prosthesis should also be carried out by CAD/CAM technology and represents merely a copying process of the temporary prosthesis into the definitive prosthesis by a different material.

In spite of all the benefits of these new methods, the dentist's working procedures will have to be adapted to the methods of CAD/CAM and milling technology. These include appropriate tooth preparations with the creation of a continuous preparation margin, which is clearly recognisable to the scanner, for example in the form of a chamfer preparation. Shoulderless preparations and parallel walls should be avoided. On the basis of present knowledge, a tapered angle of between $4^{\circ}$ to $10^{\circ}$ is recommended..$^{30}$ Subsections and irregularities

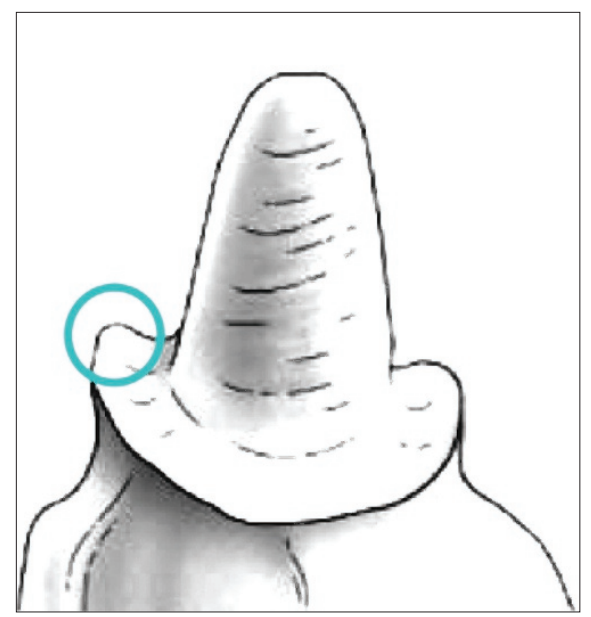

Fig. 6 Reverse bevel preparation making the preparation border hardly detectable by the CAD-software

on the surface of the prepared tooth as well as the 'creation of troughs' with a reverse bevel preparation margin can be inadequately recognised by many scanners (Fig. 6). In addition, sharp incisor and occlusal edges are to be rounded. Sharp and thinly extending edges as well as $90^{\circ}$ shoulders in a ceramic restoration can result in a concentration of tension; in addition sharp edges cannot be milled exactly using rounded grinders in the milling device. The diameter of the smallest grinder is $1 \mathrm{~mm}$ in most systems, so structures smaller than $1 \mathrm{~mm}$ cannot be milled precisely. The result is an inaccurate fit.

A 360 degree shoulder or chamthe appropriate marginal preparation geometries for CAD/CAM produced all-ceramic restorations. In the case of FPDs, the abutment teeth cannot show any divergence.

The precision of fit that can be achieved with the assistance of CAD/CAM systems is reported to be $10-50 \mu \mathrm{m}$ in the fer preparation is considered to be 
marginal area..$^{829,32-34}$ Thus, the demands of the literature concerning marginal adaptation of dental restorations can be reached with this technology; ${ }^{35,36}$ in addition, this production process achieves an industrial standard that does not have to deal with the variations of manually produced prostheses. ${ }^{23}$

\section{EVALUATION - ADVANTAGES AND DISADVANTAGES OF COMPUTER-ASSISTED PRODUCTION}

CAD/CAM technologies have started a new age in dentistry. The quality of dental prostheses has improved significantly by means of standardised production processes. This makes very efficient quality management possible. On the one hand it increased the productivity tremendously and changed dental laboratories from manufacturers to modern computerised production centres. On the other hand this increase in productivity leads to a competitive capability to produce dental prostheses independent of the manufacturing site, which might be a major factor for the high wage countries to keep business volume in the country. Last but not least CAD/CAM technology has made it possible to machine interesting new materials like the high performance ceramics and titanium with high accuracy.

However, some drawbacks of this fabrication technology have to be mentioned. The high investment for machines might overextend the budget of smaller laboratories. Some applications are limited due to software and production procedures.

CAD/CAM technology has already changed dentistry and will replace more and more of the traditional techniques in fabricating dental restorations.
1. Otto T, De Nisco S. Computer-aided direct ceramic restorations: a 10- year prospective clinical study of Cerec CAD/CAM inlays and onlays. Int J Prosthodont 2002; 15: 122-128.

2. Reiss B. Clinical results of Cerec inlays in a dental practice over a period of 18 years. Int J Comput Dent 2006; 9: 11-22.

3. Sjögren G, Molin M, van Dijken J W. A 10-year prospective evaluation of CAD/CAM-manufactured (Cerec) ceramic inlays cemented with a chemically cured or dual-cured resin composite. Int J Prosthodont 2004; 17: 241-246.

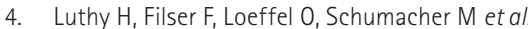
Strength and reliability of four unit all-ceramic posterior bridges. Dent Mater 2005; 21: 930-937.

5. May K B, Russell M M, Razzoog M E, Lang B R. Precision of fit: the Procera AllCeram crown. J Prosthet Dent 1998; 80: 394-404.

6. Raigrodski A J. All-ceramic full-coverage restorations: concepts and guidelines for material selection. Pract Proced Aesthet Dent 2005; 17: 249-256, quiz 258 .

7. Raigrodski A J, Chiche G J. The safety and efficacy of anterior ceramic fixed partial dentures: a review of the literature. J Prosthet Dent 2001; 86: $520-525$.

8. Reich S, Wichmann M, Nkenke E, Proeschel P. Clinical fit of all-ceramic three-unit fixed partial dentures, generated with three different CAD/CAM systems. Eur J Oral Sci 2005; 113: 174-179.

9. Mehl A, Gloger W, Kunzelmann KH, Hickel R. A new optical 3-D device for the detection of wear. J Dent Res 1997; 76: 1799-1807.

10. Webber B, McDonald A, Knowles J. An in vitro study of the compressive load at fracture of Procera AllCeram crowns with varying thickness of veneer porcelain. J Prosthet Dent 2003; 89: 154-160.

11. Reiss B. Cerec standard 3-D occlusal contouring in comparison with the new biogeneric occlusal morphing: a case report. Int J Comput Dent 2007; 10: 69-75.

12. Sorensen J A, Choi C, Fanuscu M I, Mito W T. IPS Empress crown system: three-year clinical trial results. J Calif Dent Assoc 1998; 26: 130-136.

13. Sorensen J A, Cruz M, Mito W T, Raffeiner 0 et al. A clinical investigation on three-unit fixed partia dentures fabricated with a lithium disilicate glassceramic. Pract Periodontics Aesthet Dent 1999: 11: 95-106.

14. Taskonak B, Sertgoz A. Two-year clinical evaluation of lithia-disilicate based all-ceramic crowns and fixed partial dentures. Dent Mater 2006; 22: 1008-1013.

15. Tinschert J, Natt G, Mautsch W, Augthun M, Spiekermann H. Fracture resistance of lithium disilicate-, alumina-, and zirconia-based three-unit fixed partial dentures: a laboratory study. Int J Prosthodont 2001; 14: 231-238.

16. Sorensen J A, Kang S K, Avera S P. Porcelaincomposite interface microleakage with various porcelain surface treatments. Dent Mater 1991; 7: $118-123$.

17. Sorensen J A, Munksgaard E C. Ceramic inlay movement during polymerization of resin luting cements. Eur J Oral Sci 1995; 103: 186-189.

18. Vult von Steyern P, Jonsson O, Nilner K. Five-year evaluation of posterior all-ceramic three-unit (InCeram) FPDs. Int J Prosthodont 2001; 14: 379-384

19. Raigrodski A J, Chiche G J. All-ceramic fixed partial dentures, Part I: in vitro studies. J Esthet Restor Dent 2002; 14: 188-191.

20. Raigrodski A J, Chiche G J, Swift E J Jr. All-ceramic fixed partial dentures, Part III: clinical studies. J Esthet Restor Dent 2002; 14: 313-319.

21. Dunn M. Biogeneric and user-friendly: the Cerec 3D software upgrade V3.00. Int J Comput Dent 2007; 10: 109-117.

22. Tinschert J, Natt G, Hassenpflug S, Spiekermann H. Status of current CAD/CAM technology in dental medicine. Int J Comput Dent 2004; 7: 25-45.

23. Tinschert J, Zwez D, Marx R, Anusavice KJ. Structural reliability of alumina-, feldspar-, leucite-, mica- and zirconia-based ceramics. J Dent 2000; 28: 529-535.

24. Curtis A R, Wright A J, Fleming G J. The influence of surface modification techniques on the performance of a Y-TZP dental ceramic. J Dent 2006; 34: 195-206.

25. Kosmac T, Oblak C, Jevnikar P, Funduk N, Marion L. The effect of surface grinding and sandblasting on flexural strength and reliability of Y-TZP zirconia ceramic. Dent Mater 1999; 15: 426-433.

26. Swain M V. Limitation of maximum strength of zirconia-toughened ceramics by transformation toughening increment. J Am Ceramic Soc 1985; 66: 358-362.

27. Swain M V Hannink $\mathrm{R} \mathrm{HJ}$. Metastability of the martensitic transformation in a $12 \mathrm{~mol} \%$ ceriazirconia alloy: grinding studies. J Am Ceramic Soc 1989; 72: 1358-1364.

28. Sailer I, Feher A, Filser F, Gauckler LJ et al. Five year clinical results of zirconia frameworks for posterior fixed partial dentures. Int J Prosthodont 2007: 20: 383-388.

29. Tinschert J, Natt G, Mautsch W, Spiekermann $H$, Anusavice K J. Marginal fit of alumina- and zirconia-based fixed partial dentures produced by a CAD/CAM system. Oper Dent 2001; 26: 367-374.

30. Vult von Steyern P, Carlson P, Nilner K. All-ceramic fixed partial dentures designed according to the DC-Zirkon technique. A 2-year clinical study. J Oral Rehabil 2005; 32: 180-187.

31. Luthardt R G, Holzhuter M, Sandkuhl 0 et al. Reliability and properties of ground Y-TZP-zirconia ceramics. J Dent Res 2002; 81: 487-491.

32. Bindl A, Mormann W H. Marginal and internal fit of all-ceramic CAD/CAM crown-copings on chamfer preparations. J Oral Rehabil 2005; 32: 441-447.

33. Stappert C F, Denner N, Gerds T, Strub J R. Marginal adaptation of different types of all-ceramic partial coverage restorations after exposure to an artificial mouth. Br Dent J 2005; 199: 779-783.

34. Sulaiman F, Chai J, Jameson L M, Wozniak W T. A comparison of the marginal fit of In-Ceram, IPS Empress, and Procera crowns. Int J Prosthodont 1997; 10: 478-484.

35. McLean J W. Polycarboxylate cements. Five years' experience in general practice. Br Dent J 1972; 132: $9-15$.

36. McLean J W, von Fraunhofer J A. The estimation of cement film thickness by an in vivo technique. BrDent J 1971; 131: 107-111. 